\section{Reply to A. Wong et al}

We appreciate the insightful discussion of Wong et al ${ }^{1}$ inspired by our recent commentary on pseudoprogression and immunerelated response in solid tumors. ${ }^{2}$ Specific criteria for immunerelated responses have been created to capture the dynamic patterns of response observed in patients who have been treated with immunotherapeutic agents. ${ }^{3}$ Wong et al raise multiple questions about the challenging role of palliative care because increasing numbers of oncology patients receive these novel drugs near the end of life.

Patients and practitioners continue to gain wider access to immunotherapeutic agents through numerous clinical trials. In addition, immune checkpoint inhibitors are now available outside clinical trials through drug approvals in selected tumor indications. These novel therapies, with distinct mechanisms of action and immune-related patterns of response, have opened the door for further critical conversations for patients with cancer.

In this era of immuno-oncology, the concept of value in cancer care remains paramount. ${ }^{4,5}$ Patients and physicians pursue these new therapies in search of clinical efficacy-measured by alleviation of clinical symptoms, tumor regression, durability of response, and survival benefit. At the level of an individual patient and provider, the potential promise of these agents is constantly weighed alongside potential impacts on quality of life, including regular clinical assessments, physical adverse effects, and financial cost. At a broader level, societal determinations of costeffectiveness and medical resource allocation may also vary across different health systems and regions of the world. ${ }^{6}$

Increasingly, patients remain active advocates when evaluating their treatment options. Whether they are early in their treatment courses or in advanced-stage disease, patients approach their provider teams for guidance when deciding whether to pursue novel and/or experimental therapies. Oncologists and palliative care providers perform a pivotal role in increasing awareness of immune-related patterns of response and guiding transitions to survivorship follow-up, next treatments, and supportive care. The rising numbers of patients treated on immunotherapy and emerging information about responders across solid tumor types will provide new knowledge about survivorship in this population. In the field of immunotherapy, there are many stakeholders. Together, clinicians, investigators, regulatory agencies, drug developers, and ultimately our patients, are driving important ongoing conversations to improve cancer care.

\section{Victoria L. Chiou}

Center for Cancer Research, National Cancer Institute, Bethesda, MD

\section{Mauricio Burotto}

Clinica Alemana de Santiago, Universidad del Desarrollo, Santiago, Chile

\section{AUTHORS' DISCLOSURES OF POTENTIAL CONFLICTS OF INTEREST}

Disclosures provided by the authors are available with this article at www.jco.org.

\section{REFERENCES}

1. Wong $A$, Fullerton $S$, Spruyt $O$, et al: Integration of immuno-oncology and palliative care. J Clin Oncol 34:1561-1562, 2016

2. Chiou VL, Burotto M: Pseudoprogression and immune-related response in solid tumors. J Clin Oncol 33:3541-3543, 2015

3. Wolchok JD, Hoos A, O'Day S, et al: Guidelines for the evaluation of immune therapy activity in solid tumors: Immune-related response criteria. Clin Cancer Res 15:7412-7420, 2009

4. Schnipper LE, Davidson NE, Wollins DS, et al: American Society of Clinical Oncology statement: A conceptual framework to assess the value of cancer treatment options. J Clin Oncol 33:2563-2577, 2015

5. Saltz LB: The value of considering cost, and the cost of not considering value. J Clin Oncol 2015 [epub ahead of print on December 14, 2015]

6. Fojo T, Lo AW: Price, value, and the cost of cancer drugs. Lancet Oncol 17: 3-5, 2016

DOI: 10.1200/JCO.2015.66.2031; published online ahead of print at www.jco.org on February 29, 2016. 


\section{AUTHORS' DISCLOSURES OF POTENTIAL CONFLICTS OF INTEREST}

\section{Reply to A. Wong et al}

The following represents disclosure information provided by authors of this manuscript. All relationships are considered compensated. Relationships are self-held unless noted. I = Immediate Family Member, Inst = My Institution. Relationships may not relate to the subject matter of this manuscript. For more information about ASCO's conflict of interest policy, please refer to www.asco.org/rwc or jco.ascopubs.org/site/ifc.

\section{Victoria L. Chiou}

Employment: National Cancer Institute, Center for Cancer Research, National Institutes of Health

\section{Mauricio Burotto}

No relationship to disclose 